\title{
Evaluation of work-related accidents among Hamadan construction workers
}

\author{
Maedeh Kamalvandi ${ }^{1}$, Iraj Mohammadfam², Rozita Farhadi ${ }^{3}$, Mohsen Jalilian ${ }^{4}$, Nematullah \\ Kurd $^{1 *}$
}

1. Department of Occupational Health Engineering, Faculty of Health, Ilam University of Medical Sciences, Ilam, Iran

2. Research Centre for Health Sciences, Faculty of Health, Hamadan University of Medical Sciences, Hamadan, Iran

3. Department of Occupational Health Engineering, Faculty of Health, Kermanshah University of Medical Sciences, Kermanshah, Iran

4. Department of Public Health, Faculty of Health, Ilam University of Medical Sciences, Ilam, Iran

*Corresponding author:Tel: +98 9183354890 Fax: +98

Address: Department of Occupational Health Engineering, Faculty of Health, Ilam University of Medical

Sciences, Ilam, Iran

E-mail: kurd-n@medilam.ac.ir

Received; 2017/07/8 revised; 2017/08/6 accepted; 2017/09/16

\begin{abstract}
Introduction: construction is one of the most important industries in which many workers start on activity. Sometimes, these industries workers are victims of different occupational accidents and injuries. Therefore, the aim of this study was to determine the frequency and underlying reasons in construction accidents.
\end{abstract}

Materials and methods: In this descriptive - analytical study, all construction workers $(\mathrm{n}=$ 347) who encountered with occupational accident were studied in Hamadan city, west of Iran. The data were extracted from health profiles of injured workers by checklist. Data were analyzed with SPSS 16 by applying of Chi square and Logistic regression tests at the significant level of $\mathrm{P}<0.05$.

Results: During 2007-2010, 347 workers encountered with construction accidents and seven of them were died. Finding showed that fall and slip were cause of $36.59 \%$ of accidents. Also, carelessness was major predictor factor related to $80.96 \%$ of accidents. According to the results, $36.02 \%$ of these accidents were happened at 15.00 and 18.00 PM.

Conclusion: Develop and discussion about organizing public policies is suggested to implement work safety programs for construction workers.

Keywords: Accidents, Work-related injuries, Construction workers

\section{Introduction}

Construction industries are playing a basic role in development of economics of many countries and provide required substructures for development of other economic parts (1). Although, work related accidents for this industries workers are decreasing but many of these accidents is happen at certain intervals in Construction industries $(2,3)$.

Construction accidents are cause of some adverse complication such as fracture, amputation and death in which lead to financial loss and reduction of production (4). Occupational accidents in mentioned industry are vast because of this kind of human activity has many features of creating accidents, such as working in different construction sites, different work conditions between sites, vast suffering of processes, machinery and a lot of tools with different types of risks, seasonal 
features of Construction and effects of climatic conditions of work $(5,6)$.

Accidents which occurred in this sector of industry were reported in worldwide. For example, in Taiwan, 14 death per 1000 of construction workers were reported in 2008 (7). In United States, totally 150'000 injuries, disease and lost working-hour were documented (8). Bomel et al (2001) was reported which $40 \%$ of accidents in Japan, 25\% in UK and 50\% in Ireland were happened in sector of construction activities that demonstrate high suffering levels of mortality and injuries (9).

Construction accidents had imposed costs on communities. According to the center of protection of worker's rights (CPWR) report, mean level of compensation payment resulted from Construction workers injury was two times more than other industries (8). In Iran, the trend of accidents is same as worldwide because of the absence of accurate system of recording the accidents in Construction activities, reliable information about happening accidents is not available. According to the reports published by the social security organization (SSO) in 2003, about 150000 occupational injuries were recorded in Iran which unfortunately, 1148 (7\%) were lead to death (9-10). Based on the published data from Iran, the much numbers of work related injuries were occur in construction industries and less than $12 \%$ of the workers are working in construction sectors (11). With regard to different consequences of accidents such as amputation, deformity, fracture, injury the worker, social securing organization, the society will encounter with a lets of material and spiritual damages of economy and society in next years. Therefore, the aim of this study was to investigate the number of injuries, cause and the type of injury among workers of construction industries during 2007-2010 years in Hamadan city, the west of Iran.

\section{Materials and methods}

This research was a cross-sectional study and the participants were the employees of the construction activities of Hamadan city. Data were collected by using of check list. All data were extracted from injured person's health profiles. The checklist was assessed several variables such as age, gender, marital status, insurance coverage, job history, working shift, site of accident, accident consequences. The data were analyzed by SPSS.21software by conduct of chi-squire statistical test and logistic regression. In all of calculation, $\alpha<0.05$ was considered as significant.

\section{Results}

According to the data were recorded in social securing organization and labor and social affairs office in totally, 347 occupational accidents were happened for construction workers in Hamadan city during 2007-2010 years. The mean age of injured workers was $33.79 \pm 13.6$ years (ranged 16-76 years) and the mean of work experience was $12.5 \pm 3.1$ years. Fifty six percent of total recorded accidents in these organizations were occurred in construction activities during 2007- 2010 years.

The distributions of work related death and non-fatal injuries in construction activities by age are presented in Figure 1. The negative correlation was found between age and likelihood of accidents $(\mathrm{P}=$ $0.004)$. 


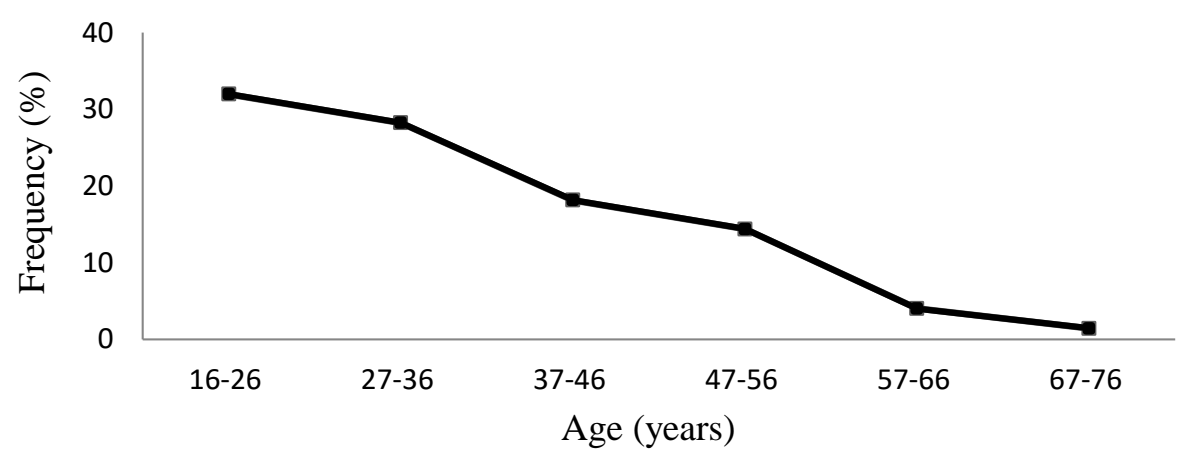

Figure 1. Number of total accidents, serious and fatals by age, Hamadan (2007-2010).

Based on extracted data, Accidents were distributed in all seasons, alternately although their highest point of happening was in the middle and at the end of summer and in the early of autumn (spring $=57$, summer $=109$ and autumn $=113$ case). Finding related to the working shifts showed that highest percent of accidents were occurred in morning, afternoon and night shifts $(63.11,35.44$ and $0.28 \%$ ) respectively. the human errors were the most important factors related to the construction injuries (Figure 2).

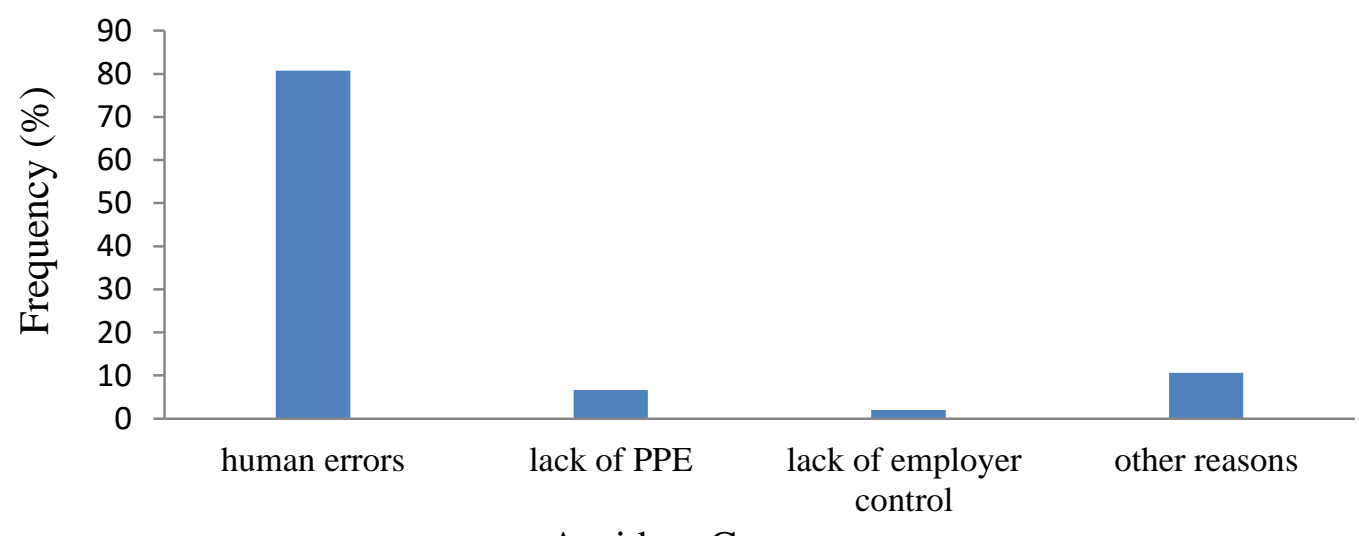

Accident Causes

Figure 2. Distribution of accidents causes $(n=347)$.

All injured persons were men and 71.87 percent of them have got married. There was no recorded information about educational status, therapeutic insurance status and sort of the job at the time of the accident. Furthermore, results have indicated that most of the accidents were occurred in morning shift.

With regarded to factors related to accident occurrence, the most importance type of the work-related injuries in construction workers in study sample was sleep induced falls which accounted for 127 (36.59\%) of accidents (Table 1).

Distribution of the injured related to suffered organ showed that most of injuries were occurred in hands and feet with the frequencies of $79(29.76 \%)$ and $69(19.88 \%)$ respectively. Regarding to accidents' consequent, 240 cases $(69.16 \%)$ was treatment and 7 cases $(2.01 \%)$ lead to death (Table 3). 
Table 1. Distribution of accidents type ( $n=347)$.

\begin{tabular}{lcc}
\hline Accident type & Number & Percent (\%) \\
\hline Fall and slip & 127 & 36.59 \\
Falling objects & 44 & 12.68 \\
Being contused & 29 & 8.35 \\
Caught between/ clamped & 26 & 7.49 \\
Electric shocks & 4 & 1.15 \\
Other type & 117 & 33.71 \\
\hline
\end{tabular}

Table 3. The Severity of Work-Related Injuries $(n=347)$.

\begin{tabular}{lc}
\hline Accident results & Percent (\%) \\
\hline Death & 2.01 \\
Fractures & 10.37 \\
Debility & 2.88 \\
Internal bleeding & 2.3 \\
Injuring and wound & 8.06 \\
Recovery & 69.16 \\
Other & 5.22 \\
\hline
\end{tabular}

\section{Discussion}

Although implementation of this study may be effecting in information about the number of occupational injuries and accidents in construction sites, it is not a preventing factor until a compiled presentation program of accidents are not organized in construction sites, thus we will observe accidents happening in this important sector of industry.

According to data analyzing during 20072010 in Hamadan, 347 workers encountered with construction accidents among which 250 and 91 cases were recorded in labor and social affairs office and social securing organization, respectively. In the case of these accidents, total numbers of death were 7 cases. In other words, the rate of death was 2.3 per 100 workers, which were higher than other countries such as Taiwan with 0.29 per 1000 workers, and other European countries (7). Many factors had contributed in the death revealing such as there is no following protection rules by employers, training workers about safety points and following safety principles by workers.

The rate of accidents happening has increased with approaching to increase in weather temperature that it may be resulted from increasing of working force in the sector of construction activities because of betterment of climatic conditions. According to the age of suffered workers, more than 31 percent of accidents were occurred for workers who have less than 25 years old. These results were different from the finding of vazirinejad and Miguel study $(8,12)$. But were consist with finding of vatani-shoja et al study (13).

Fracture was common consequence of construction accidents in studied sample. This finding was consisting with results of previous research which were conducted in several fields. For example, colak, Bahrampoor and vatani-shoja et al had reported that fractures were more than $70 \%$ percent of accidents consequences in their studies $(11,13,14)$. Highest frequencies of causes of accidents were carelessness with the frequency of 280 cases $80.69 \%$ ) and deficiency or lack of suitable fence, respectively. These finding were accordance with results of vazirinejad and vatani-shoja $(12,13)$.

Findings of this study have indicated that the most important factor that directly caused to accident happening was individual's falling from height. This finding was in accordance with results of performed studies in this field (15-17). 
Falling and dropping commonly are depended on following reasons: a) worker's horizontal monument ( for example, at the time of material displacement or cleaning), b) harmful touch with construction tools and timber (for example , scaffolding, openings, ceilings , c) unsafe works (when construction is unstable or lacks protection procedures in the site, d) lack of individual's protection tools (18). Therefore, it is necessary to workers to effectively comply with safety rules, use full equipment (locking hook, rope and scaffolding) during work in height in order to prevent falling or decrease severity of injuries. Also, using of protection tools such as contact point, keeping belt can minimize accidents which resulted from falling.

Finally, with regard to results of the study it is conclude that implementation of workers educational programs and use of standard protection tools to sort of work and also supervising control on using of these tools by workers can lead to significant decrees in the rate of accident happening in construction industries.

\section{Conclusion}

Regarding to mention frequency of construction accidents in Hamadan and all

\section{References}

1. Yoon SJ, Lin HK, Chen G, Yi S, Choi J, Rui Z. Effect of occupational health and safety management system on work-related accident rate and differences of occupational health and safety management system awareness between managers in South Korea's construction industry. Saf Health Work. 2013;4(4):201-9.

2. Al Haadir S, Panuwatwanich $K$. Critical success factors for safety program implementation among construction companies in Saudi Arabia. Procedia Engineer. 2011; 14:148-55. over Iran in comparison with other countries, specifically in developed countries, and with respect to the economic and social effects of construction accidents, lower rate of these accidents can be achieved with following actions:

Safety in construction activities must be organized and integrated within all project groups, from designers and engineers to train and enhance of skilled of workers.

General commitment to establish a system of safety management to attract workers participation in safety programs.

Forming skill through designing and using of individual protection tools is necessary . Usually individual protection tools are inappropriate and nonfunctional, there for standard protection tools must be provided for workers.

Designing and implementing of safety programs for long-term strategic management of accidents in the country.

Effort in the direction of strengthening active markers, specially promoting safety cultural level among whole society (19).

\section{Acknowledgements}

This project was supported by Hamadan University of Medical Sciences. The authors are grateful of research deputy for financial support.

3. Mitropoulos P, Abdelhamid TS, Howell GA. Systems model of construction accident causation. J Construc Engineer Manag. 2005; 131(7):816-25.

4. Moradinazar M, Kurd N, Farhadi R, Amee V, Najafi F. Epidemiology of work-related injuries among construction workers of Ilam (Western Iran) during 2006-2009. Iran Red Crescent Med J. 2013; 15(10):1-4.

5. Hino $\mathrm{Y}$, Ohdo $\mathrm{K}$, Takanashi S, Takahashi H. International survey on prevention system of labor accidents at 
construction site. Procedia Engineer. 2011; 14:1205-11.

6. Hola B. General model of accident rate growth in the construction industry. $\mathrm{J}$ Civil Engineer Manag. 2007; 13(4):255-64.

7. Liao C-W. Pattern analysis of seasonal variation in occupational accidents in the construction industry. Procedia Engineer. 2012; 29:3240-4.

8. Waehrer GM, Dong XS, Miller T, Haile E, Men Y. Costs of occupational injuries in construction in the United States. Accid Anal Prev. 2007;39(6):1258-66.

9. Mehrparvar A, Mirmohammadi S, Ghovve M, Hajian H, Dehghan M, Nabi Meybodi R, et al. Epidemiologic study of occupational accidents recorded in Yazd province in the years 2007-2008. Occup Med J. 2012; 3(3):54-62.

10. Mohammadfam I, Moghimbeigi A. Evaluation of injuries among a manufacturing industry staff in Iran. $\mathbf{J}$ Res Health Sci. 2009; 9(1):7-12.

11. Bahrampour A, Jafari Nodoushan R, Vatani Shoaa J. Five-year epidemiological study and estimation of accidents distribution in construction industry workers in yazd city by the year 2011 by applying time series model. J Kerman Uni Med Sci. 2009;16(2):156-64. (Persian)

12. Vazirinejad R, Esmaeili A, Kazemi M. Occupational accidents in construction industry among people reffering to lobor and social affairs office Rafsanjan, during 2000-2002. J Rafsanjan Uni Med Sci. 2005; 4(4):326-31. (Persian)
13. Vatani SJ, Salasi M, Bahrampor A, Raei M, Asadi M, Jafari NR, et al. An epidemiological study of accidents among construction workers in Kerman. J Knowledge Health. 2011; 5(4):32-6.

14. Colak B, Etiler N, Bicer U. Fatal occupational injuries in the construction sector in Kocaeli, Turkey, 1990-2001. Ind Health. 2004;42(4):424-30.

15. Sadeghain M, Farid RA, Dormohammadi A, Aghaei HA, Rahmani A, Farhadi R, et al. Assessment of the prevalence of occupational accidents and their influential actors in an electricity distribution company during a fiveyear period. Electron Physician. 2013; 5(2):643.

16. Dong XS, Fujimoto A, Ringen K, Men Y. Fatal falls among Hispanic construction workers. Accid Anal Prev. 2009;41(5):1047-52.

17. Haslam RA, Hide SA, Gibb AG, Gyi DE, Pavitt $\mathrm{T}$, Atkinson $\mathrm{S}$, et al. Contributing factors in construction accidents. Appl Ergon. 2005;36(4):401-15.

18. Cheng CW, Lin CC, Leu SS. Use of association rules to explore causeeffect relationships in occupational accidents in the Taiwan construction industry. J Saf Sci. 2010; 48(4):436-44.

19. Sokas RK, Jorgensen E, Nickels L, Gao W, Gittleman JL. An intervention effectiveness study of hazard awareness training in the construction building trades. Public Health Rep. 2009;124 Suppl 1:160-8. 